A.

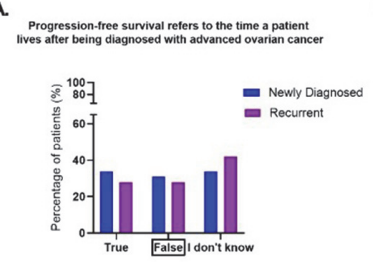

B.

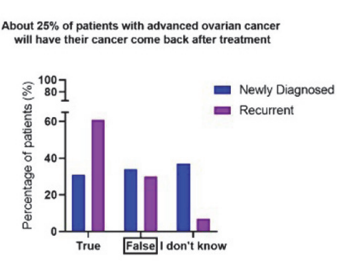

c.

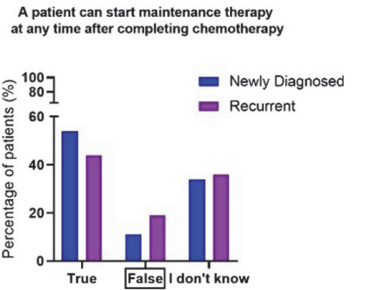

D.

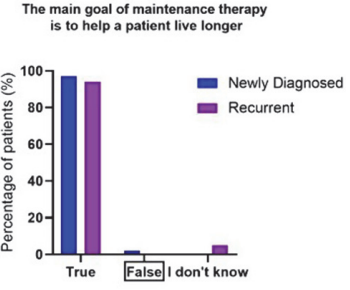

Abstract EPV186/\#240 Figure 1

${ }^{*}$ Correct answers selected on each contingency table.

\begin{tabular}{|c|c|c|c|}
\hline & $\begin{array}{c}\text { Newly } \\
\text { Diagnosed }\end{array}$ & $\begin{array}{c}\text { Already } \\
\text { Recurred }\end{array}$ & Total \\
\hline \multicolumn{4}{|l|}{ Age } \\
\hline Median Age & 60.2 & 65.5 & 62.3 \\
\hline Total & $35(40.2 \%)$ & $52(60.0 \%)$ & $87(100.0 \%)$ \\
\hline \multicolumn{4}{|l|}{ Race } \\
\hline White & $31(88.6 \%)$ & $43(83.0 \%)$ & $74(85.0 \%)$ \\
\hline Black or African American & $1(2.9 \%)$ & $3(6.0 \%)$ & $4(5.0 \%)$ \\
\hline Other & $3(8.6 \%)$ & $6(11.5 \%)$ & $9(10.3 \%)$ \\
\hline Total & $35(100.0 \%)$ & $52(100.0 \%)$ & $87(100.0 \%)$ \\
\hline \multicolumn{4}{|l|}{ Education } \\
\hline$\leq$ High School Graduate & $1(2.9 \%)$ & $11(21.1 \%)$ & $12(14.0 \%)$ \\
\hline $\begin{array}{l}\text { Some College or Technical } \\
\text { School }\end{array}$ & $14(40.0 \%)$ & $11(21.1 \%)$ & $25(29.0 \%)$ \\
\hline $\begin{array}{l}\text { College Graduate/Post- } \\
\text { Graduate }\end{array}$ & $20(57.1 \%)$ & $30(58.0 \%)$ & $50(57.5 \%)$ \\
\hline Total & $35(100.0 \%)$ & $52(100.0 \%)$ & $87(100.0 \%)$ \\
\hline \multicolumn{4}{|l|}{ Employment } \\
\hline Full-time employed & $10(28.6 \%)$ & $12(23.1 \%)$ & $22(25.3 \%)$ \\
\hline Part-time employed & $3(8.6 \%)$ & $1(2.0 \%)$ & $4(5.0 \%)$ \\
\hline Homemaker & $4(11.4 \%)$ & $5(10.0 \%)$ & $9(10.3 \%)$ \\
\hline Retired & $13(37.1 \%)$ & $33(63.5 \%)$ & $46(53.0 \%)$ \\
\hline Disabled/Unemployed & $5(14.3 \%)$ & $1(2.0 \%)$ & $6(7.0 \%)$ \\
\hline Total & $35(100.0 \%)$ & $52(100.0 \%)$ & $87(100.0 \%)$ \\
\hline \multicolumn{4}{|l|}{ Annual household income } \\
\hline Less than $\$ 35,000$ & $4(11.4 \%)$ & $6(11.5 \%)$ & $10(11.5 \%)$ \\
\hline Less than $\$ 75,000$ & $8(23.0 \%)$ & $2(4.0 \%)$ & $10(11.5 \%)$ \\
\hline$\$ 75,000$ or more & $17(48.6 \%)$ & $33(63.5 \%)$ & $50(57.5 \%)$ \\
\hline $\begin{array}{l}\text { I prefer not to answer this } \\
\text { question }\end{array}$ & $6(17.1 \%)$ & $11(21.1 \%)$ & $17(19.5 \%)$ \\
\hline Total & $35(100.0 \%)$ & $52(100.0 \%)$ & $87(100.0 \%)$ \\
\hline
\end{tabular}

iteratively using cognitive interviews with patients. Patients with $\mathrm{OC}$ with $\geq 3$ cycles of chemotherapy and cytoreductive surgery completed the survey by email or phone. No prior background information was given to patients.

Results Clinico-demographic characteristics are shown in table $1(n=87)$. Sixty percent had recurrent disease. General knowledge about advanced OC was similar between groups. The majority of patients did not understand the purpose of MT or the definition of progression-free survival. The recurrent group showed a similar lack of knowledge in the same questions as the newly diagnosed group, with no statistically significant differences observed (figure 1).

Conclusions Our data suggests that knowledge of OC among patients is highly variable. The overall lack of understanding regarding the goal of MT even among patients who have recurred is concerning. These gaps in knowledge suggest an important role for shared decision making to improve patients' decision making about treatment of advanced OC.

\section{EPV187/\#241 EFFICACY OF PARP INHIBITORS MAINTENANCE IN OLDER PATIENTS WITH OVARIAN CANCER: A META-ANALYSIS}

${ }^{1}$ BA Maiorano*, ${ }^{2}$ MFP Maiorano, ${ }^{1} \mathrm{D}$ Ciardiello, ${ }^{1} \mathrm{MG}$ Rodriquenz, ${ }^{3} \mathrm{~A}$ Maglione, ${ }^{3} \mathrm{~N}$ Scianname', 'E Maiello. ${ }^{1}$ Foundation Casa Sollievo della Sofferenza IRCCS, Oncology, San Giovanni Rotondo, Italy; 'University of Bari 'Aldo Moro', Biomedical and Human Oncological Science, Division of Obstetrics and Gynecology, Bari, Italy; ${ }^{3}$ Foundation Casa Sollievo della Sofferenza IRCCS, Gynecology and Obstetrics, San Giovanni Rotondo, Italy

\subsection{6/ijgc-2021-IGCS.258}

Objectives In recent years, PARP inhibitors have shown to be effective as maintenance treatment in patients with advanced ovarian cancer, both in the newly diagnosed and in the recurrent setting. However, as most ovarian carcinomas develop before 65 , older patients are underrepresented in clinical trials. We performed a meta-analysis to assess the efficacy of PARP inhibitors as maintenance therapy in older patients with ovarian cancer.

Methods We systematically searched the PubMed, EMBASE, and Cochrane databases for randomized clinical trials (RCTs) concerning maintenance with PARP inhibitors in patients with newly diagnosed or recurrent, advanced, ovarian cancer. We extracted trials including hazard ratios (HRs) for progressionfree survival (PFS) stratified by patients' age (cut-off: 65 years). Results 7 phase III RCTs were selected. Olaparib, Niraparib, Rucaparib and Veliparib were administered. Among the 4099 treated patients, 1398 (34.1\%) were $\geq 65$ (894 receiving PARP inhibitors maintenance and 504 receiving placebo in the control arm). Compared to placebo, maintenance with PARP inhibitors improved PFS in older patients $(\mathrm{HR}=0.54 ; 95 \%$ CI: 0.44-0.65; P<0.00001). No differences for PFS emerged compared to the young population $(\mathrm{HR}=0.47 ; \mathrm{P}=0.22)$.

Conclusions Our meta-analysis demonstrates that maintenance with PARP inhibitors prolongs PFS compared to placebo after chemotherapy in older patients with ovarian cancer. No OS data are disposable yet. Longer follow-up and data from further studies will increase the power of our analysis.

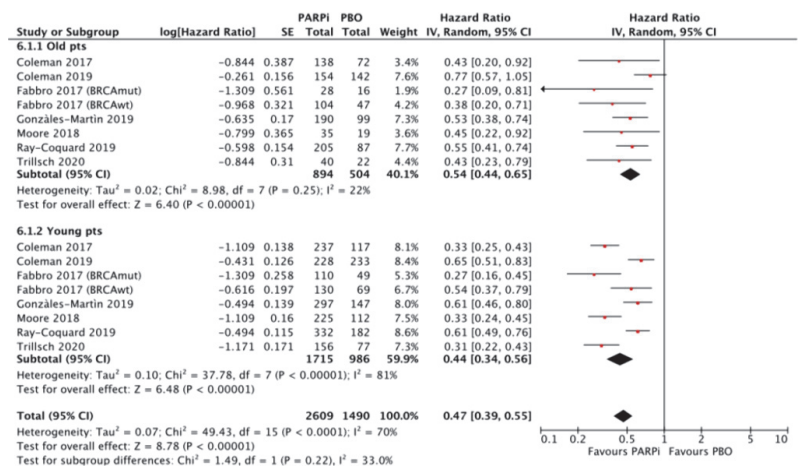

Abstract EPV187/\#241 Figure 1

\section{EPV188/\#270 ASCITES-DERIVED CORTISOL CORRELATES WITH INFLAMMATORY AND IMMUNOSUPPRESSIVE CYTOKINES IN OVARIAN CANCER PATIENTS}

${ }^{1} \mathrm{H}$ Knochenhauer*, ${ }^{2} \mathrm{~A}$ Aquino-Acevedo, ${ }^{2} \mathrm{G}$ Armaiz-Pena, ${ }^{1} \mathrm{R}$ Previs. ${ }^{1} D$ Duke University School of Medicine, Obstetrics and Gynecology, Durham, USA; ${ }^{2}$ Ponce Health Sciences University, Department of Basic Sciences (pharmacology), Ponce, Puerto Rico

10.1136/ijgc-2021-IGCS.259 

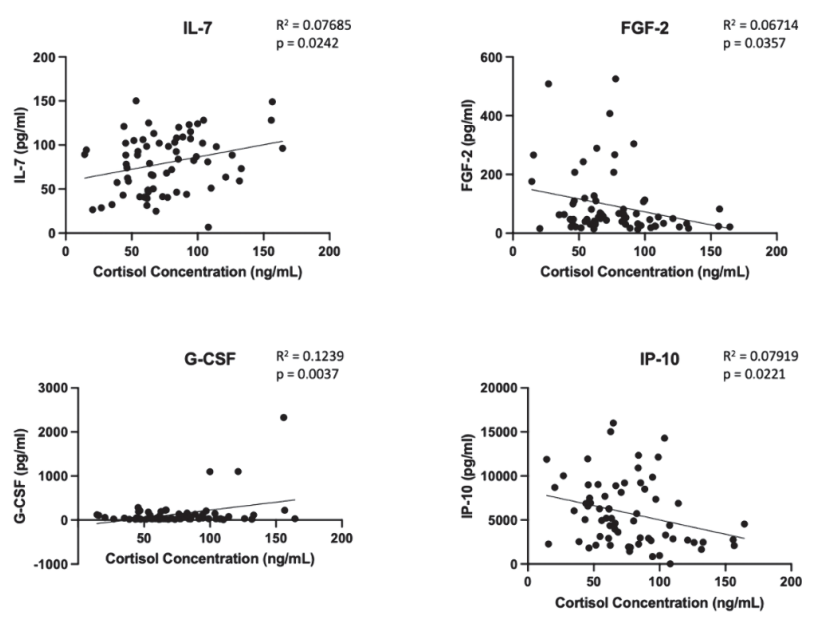

\section{Abstract EPV188/\#270 Figure 1}

Objectives Cancer patients with increased stress have worse quality of life and survival. Stress hormones such as cortisol also contribute to suppressed immune function. Stress hormones, immune cells and cytokines are evaluable in the ascites of patients with advanced stage high grade serous epithelial ovarian cancer (HGSOC). We determined the relationship between cortisol and cytokines in ascites from patients with HGSOC.

Methods Clinicodemographic information and ascites from 66 patients with primary or recurrent HGSOC were collected. Cortisol concentration was measured by ELISA using Parameter $^{\mathrm{TM}}$ Cortisol. Milliplex ${ }^{\circledR}$ MAP Human Cytokine/Chemokine Magnetic bead panel was utilized to measure cytokine levels. Significance was determined using linear regression using $\mathrm{p}<0.05$.

Results Cortisol was positively correlated with IL-7 (slope $=0.2782$, 95\% CI:0.03742-0.5189), which is a known contributor to invasiveness and metastasis of cancer. G-CSF (associated with tumor growth, angiogenesis and poor prognosis) was associated with elevated cortisol levels (slope $=3.581$, 95\% CI:1.203-5.959). Conversely, cortisol was negatively correlated with cytokines that promote immune response. This included FGF-2 (slope=-0.8821, 95\% CI:-1.703-(-0.06101)) and IP-10 (slope $=-32.44$, 95\% CI:-60.07-(-4.817)), a chemokine that plays a role in recruiting activated $\mathrm{T}$ cells to inflammatory sites.

Conclusions Our data suggest increased ascites-derived cortisol from patients with HGSOC is associated with higher levels of IL-7 and G-CSF, cytokines that promote tumor growth. Higher levels of ascites-derived cortisol correlated with lower levels of FGF-2 and IP-10, cytokines that enhance immune function. Ascites from HGSOC patients provide a window into how stress hormones impact tumor and immune cells.

\section{EPV189/\#277 TEMPORAL TRENDS OF HEALTHCARE SYSTEM COSTS AND UTILIZATION RELATED TO OVARIAN CANCER DIAGNOSIS IN THE UNITED STATES}

${ }^{1} \mathrm{~S}$ Huepenbecker*, ${ }^{2} \mathrm{~S} \mathrm{Fu},{ }^{2} \mathrm{H}$ Zhao, ${ }^{3} \mathrm{~K}$ Primm, ${ }^{1} \mathrm{C}$ Sun, ${ }^{2} \mathrm{~S}$ Giordano, ${ }^{1} \mathrm{~L}$ Meyer. ${ }^{1} \mathrm{MD}$ Anderson Cancer Center, Gynecologic Oncology and Reproductive Medicine, Houston, USA; ${ }^{2}$ MD Anderson Cancer Center, Health Services Research, Houston, USA; ${ }^{3}$ MD Anderson Cancer Center, Epidemiology, Houston, USA

10.1136/ijgc-2021-IGCS.260
Objectives To describe healthcare system costs and utilization between symptomatic presentation and ovarian cancer diagnosis in the United States.

Methods A population-based study of the Surveillance, Epidemiology, and End Results (SEER)-Medicare database was conducted on patients $\geq 66$ years old with stage II-IV epithelial ovarian cancer between 1992-2015 with at least one of the following diagnosis codes in the year before diagnosis: abdominal pain, bloating, difficulty eating, and/or urinary symptoms. The outcomes were cost and type of healthcare system utilization between first symptomatic claim and cancer diagnosis date for any reason. Jonckheere-Terpstra and Cochran-Armitage tests evaluated trends over time.

Results Among 13,872 women, the most common imaging was CT (67.6\%), followed by pelvic ultrasound (49.5\%), MRI (4.2\%), and PET (1.2\%). Between 1992-2015, frequency of ultrasound decreased $(\mathrm{p}<.001)$ while CT, MRI, PET, and CA125 increased $(p<.001)$. In the overall cohort, median cost per month was $\$ 13,941$ for hospitalizations, $\$ 2041$ for outpatient visits, and $\$ 218$ for emergency room (ER) visits. Median monthly total, inpatient, and outpatient costs decreased $(\mathrm{p}<.001)$ while ER costs increased over time $(\mathrm{p}<.001)$. The number of outpatient visits $(\mathrm{p}<.001)$ and frequency of ER visits $(p<.001)$ increased while frequency of hospitalizations $(p<.001)$ decreased over time. Median hospital length of stay decreased from 10 days in 1992 to 5 days in 2015 ( $\mathrm{p}<.001)$.

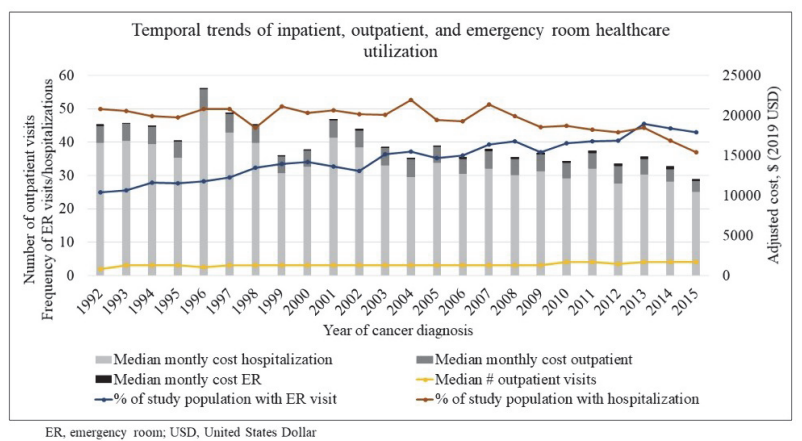

Abstract EPV189/\#277 Figure 1 Temporal trends of inpatient, outpatient, and emergency room healthcare utilization

Conclusions Healthcare utilization costs between symptomatic presentation and ovarian cancer diagnosis have decreased over time and reflect the trends in fewer and shorter hospitalizations and increased use of ER and outpatient management during the evaluation of symptoms of women with ovarian cancer.

\section{EPV190/\#320 PROGNOSTIC IMPACT OF PD-L1 EXPRESSION IN EPITHELIAL OVARIAN CANCER: A COHORT OF 49 PATIENTS}

${ }^{1} \mathrm{D}$ Atallah*, ${ }^{2} \mathrm{~A}$ Khaddage, ${ }^{2} \mathrm{~L}$ Khoury, ${ }^{2} \mathrm{~V}$ Smayra, ${ }^{2} \mathrm{M}$ Akiki, ${ }^{1} \mathrm{~N}$ El Kassis, ${ }^{3} \mathrm{G}$ Chahine, ${ }^{1} \mathrm{M}$ Moubarak. ${ }^{1}$ Hôtel-Dieu de France University Hospital, Gynecologic Oncology, Beirut, Lebanon; ${ }^{2}$ Hôtel-Dieu de France University Hospital, Pathology, Beirut, Lebanon; ${ }^{3}$ Hôtel-Dieu de France University Hospital, Oncology, Beirut, Lebanon

\subsection{6/ijgc-2021-IGCS.261}

Objectives Role of checkpoint inhibitors in ovarian cancer is still unknown and results from ongoing clinical trials are still 